\title{
Erratum to: The Development Hypothesis of Women Empowerment in the Millennium Development Goals Tested in the Context of Women's Access to Land in Africa
}

\author{
Ambe J. Njoh ${ }^{1} \cdot$ Erick Ananga ${ }^{1}$
}

Accepted: 27 June 2015/Published online: 29 July 2015

(C) Springer Science+Business Media Dordrecht 2015

\section{Erratum to: Soc Indic Res \\ DOI 10.1007/s11205-015-1020-8}

Unfortunately, in the original publication of the article, the title has been published incorrectly. The correct article title should read as, "The Development Hypothesis of Women Empowerment in the Millennium Development Goals Tested in the Context of Women's Access to Land in Africa."

The online version of the original article can be found under doi:10.1007/s11205-015-1020-8.

$\triangle$ Ambe J. Njoh njoh@usf.edu

1 School of Geosciences, University of South Florida, Tampa, FL, USA 